\title{
Design and Status of the NGNP Fuel Experiment AGR-3/4 Irradiated in the Advanced Test Reactor
}

\section{HTR 2012}

\section{S. Blaine Grover}

David A. Petti

\section{October 2012}

The INL is a

U.S. Department of Energy

National Laboratory

operated by

Battelle Energy Alliance

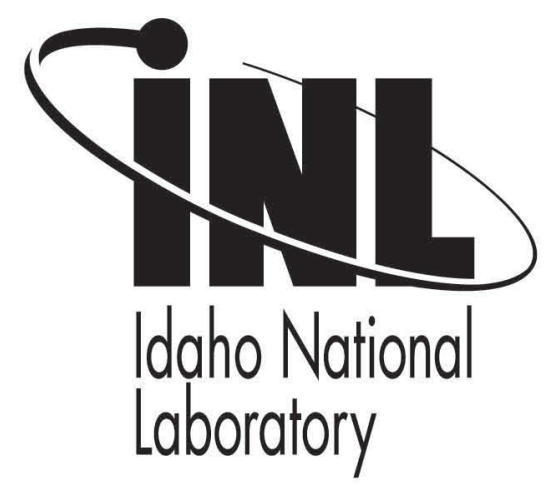

This is a preprint of a paper intended for publication in a journal or proceedings. Since changes may be made before publication, this preprint should not be cited or reproduced without permission of the author. This document was prepared as an account of work sponsored by an agency of the United States Government. Neither the United States Government nor any agency thereof, or any of their employees, makes any warranty, expressed or implied, or assumes any legal liability or responsibility for any third party's use, or the results of such use, of any information, apparatus, product or process disclosed in this report, or represents that its use by such third party would not infringe privately owned rights. The views expressed in this paper are not necessarily those of the United States Government or the sponsoring agency. 


\title{
Design and Status of the NGNP Fuel Experiment AGR-3/4 Irradiated in the Advanced Test Reactor
}

\author{
S. Blaine Grover and David A. Petti \\ Idaho National Laboratory \\ P. O. Box 1625, Idaho Falls, Idaho, 83415, United States of America \\ phone: 208-526-4489,Blaine.Grover@inl.gov
}

\begin{abstract}
The United States Department of Energy's Next Generation Nuclear Plant (NGNP) Advanced Gas Reactor (AGR) Fuel Development and Qualification Program will be irradiating up to seven separate low enriched uranium (LEU) triisotopic (TRISO) particle fuel (in compact form) experiments in the Advanced Test Reactor (ATR) located at the Idaho National Laboratory (INL). These irradiations and fuel development are being accomplished to support development of the next generation reactors in the United States, and will be irradiated over the next several years to demonstrate and qualify new TRISO coated particle fuel for use in high temperature gas reactors. The goals of the irradiation experiments are to provide irradiation performance data to support fuel process development, to qualify fuel for normal operating conditions, to support development and validation of fuel performance and fission product transport models and codes, and to provide irradiated fuel and materials for post irradiation examination (PIE) and safety testing. The experiments, which will each consist of at least six separate capsules, will be irradiated in an inert sweep gas atmosphere with individual on-line temperature monitoring and control of each capsule. The sweep gas will also have on-line fission product monitoring on its effluent to track performance of the fuel in each individual capsule during irradiation.
\end{abstract}

The first experiment (designated AGR-1) started irradiation in December 2006 and was completed in November 2009. The second experiment (AGR-2) started irradiation in June 2010 and is currently scheduled to be completed in April 2013. The third and fourth experiments have been combined into a single experiment designated AGR-3/4, which started its irradiation in December 2011 and is currently scheduled to be completed in November 2013. Since the purpose of this experiment is to provide data on fission product migration and retention in the $N G N P$ reactor, the design of this experiment is significantly different from the first two experiments, though the control and monitoring systems are very similar. The purpose and design of this experiment will be discussed followed by its progress and status to date.

\section{INTRODUCTION}

The fuel development and irradiations are being performed to support development of the next generation reactors in the United States. The AGR Fuel Development and Qualification Program, which is part of the NGNP Program, will complete the irradiation of the experiments over the next five to six years to demonstrate and qualify new LEU TRISO particle fuel for use in high temperature gas cooled reactors. The goals of the irradiation experiments are to provide irradiation performance data to support fuel process development, to qualify fuel for normal operating conditions, to support development and validation of fuel performance and fission product transport models and codes, and to 
provide irradiated fuel and materials for post irradiation examination (PIE) and safety testing [1]. The experiments will each consist of multiple separate capsules, and will be irradiated in an inert sweep gas atmosphere with individual on-line temperature monitoring and control of each capsule. The sweep gas will also have on-line fission product monitoring on its effluent to track performance of the fuel in each individual capsule during irradiation.

The experiments are specifically designed for the irradiation position location and size, as well as the specific irradiation parameters (e.g. temperature, fluence, etc.). The experiments employ an umbilical tube to house and protect the instrumentation and gas lines from the individual capsules to their connections at the reactor vessel wall to the monitoring, control and data collection systems. The overall capsule design concept and sweep gas systems used to control the capsule temperatures and monitor for fission gas release will be common to all of the AGR fuel experiments. However, the experiment capsule design, which was identical for the first two experiments (AGR-1 and AGR-2), was extensively modified for the third irradiation, which is a combination of the third and fourth experiments (designated AGR-3/4). The test train modification was performed primarily to support the specific purpose of the third irradiation, but it was also done to accommodate the different type of irradiation position (e.g. flux trap versus large B) to be used. The temperature control system for the third irradiation will also include an additional feature to inject the typical gas impurities anticipated in the coolant gas of the NGNP into the gas stream of several experiment capsules. The mission, capsule design and support systems for the AGR-3/4 experiment will be discussed followed by the status and the irradiation results to date.

\section{EXPERIMENT TYPE, MISSION AND IRRADIATION POSITION}

The following subsections detail the experiment type, mission and irradiation position within the ATR core selected for the AGR-3/4 experiment.

\section{II.A. Experiment Type}

AGR-3/4 is an instrumented lead type experiment with on-line active temperature control and fission product monitoring of the effluent gas. The other major type of irradiation experiment commonly performed in the ATR is a static capsule experiment, which has only passive temperature control and the experimental results are determined after the irradiation by examination in a hot cell. The overall concept for temperature control of the experiment capsules, the temperature control system design and the fission product monitoring system design are all essentially identical to those used on AGR-1 and AGR-2. The experiment capsules utilize an insulating gas jacket with variable mixing of helium and neon sweep gases to control temperature of the fuel during irradiation. New gas temperature control and fission product monitoring systems were installed for AGR-3/4 since the existing systems are being used to irradiate AGR-2 in parallel with the AGR-3/4 irradiation. The new systems are essentially enlarged versions of the previous systems. Since AGR-3/4 is the combination of the third and fourth experiments, the new system required twice as many temperature control channels and fission product monitors as the previous system used for the irradiation of AGR-1 and AGR-2.

\section{II.B. Mission}

The primary mission for AGR-3/4 is to determine the fission product retention behavior of the fuel compact matrix material (used to form the fuel particles into fuel compacts) and graphite materials planned for use in the NGNP. In order to complete this mission, design-to-fail (DTF) particles were included in the AGR-3/4 fuel. The DTF fuel particles provide the fission product source necessary to measure the retention behavior of the fuel compact matrix material as well as the nuclear grade graphite core components in a VHTR. Since there are many additional details of the fuel (e.g. fuel kernel and particle size, fuel compact dimensions, enrichment levels, etc.) as well as irradiation requirements (e.g. burnup levels, temperatures, etc.), the fuel will be discussed further in a separate section. This irradiation will also provide: a) fuel performance data on fission gas release from failed fuel particles; and $b$ ) irradiated fuel specimens for safety testing and PIE. In this role, the AGR-3/4 irradiation will provide valuable data for the development of improved fuel performance and fission product transport models to support source term analysis for a VHTR.

\section{II.C. Irradiation Position}

AGR-3/4 is being in irradiated the north east flux trap position in the ATR in contrast to the large B positions used to irradiate AGR-1 (B-10) and AGR-2 
(B-12). These different irradiation positions are shown in Figure 1 below. The large B positions (38 mm diameter) were initially chosen for the AGR fuel irradiations since the rate of fuel burnup and fast neutron fluence accumulation in these positions would provide an acceleration factor of between one and three times that expected in the Very High Temperature Reactor (VHTR). This acceleration factor was high enough to accomplish the irradiation within a reasonable time, but yet low enough to avoid possible premature fuel particle failures similar to those experienced in past highly accelerated particle fuel tests. AGR-1 was irradiated in the east large B position (B-10) and AGR-2 is being irradiated in the west large B position (B-12). The experiments were also originally planned to be irradiated in pairs using the B-10 and B-12 irradiation positions concurrently to minimize the schedule necessary to complete the irradiations. However, it later became apparent that in order to achieve the fuel irradiations in the time required to support the NGNP Program schedule, the irradiations would have to be accelerated. Therefore, the next six AGR experiments (AGR-3 through AGR-8) have tentatively been scheduled for irradiation in the much larger $(133 \mathrm{~mm})$ ATR north east flux trap (NEFT) position.

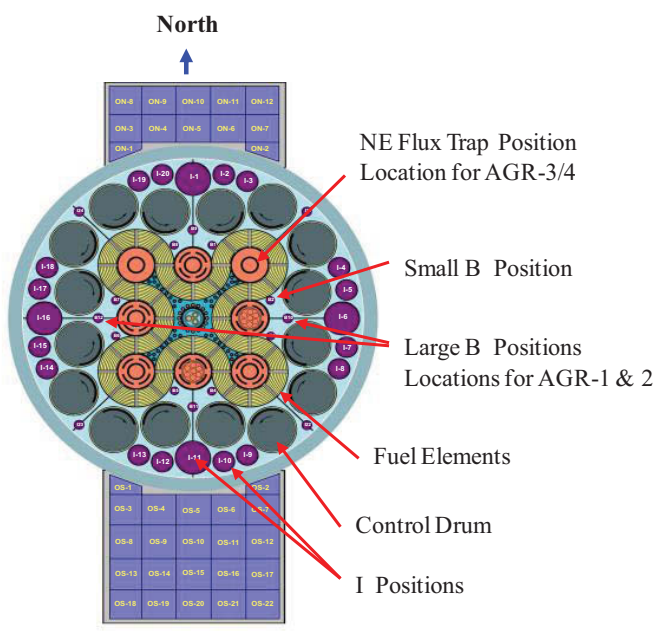

Fig. 1: ATR core cross-section showing the AGR fuel irradiation locations.

The NEFT has higher fast $\left(4.4 \times 10^{14}\right.$ versus 2.5 x $\left.10^{14} \mathrm{n} / \mathrm{cm}^{2}-\mathrm{s}\right)$ and thermal $\left(1.1 \times 10^{14}\right.$ versus $1.61 \mathrm{x}$ $10^{13} \mathrm{n} / \mathrm{cm}^{2}$-s) neutron fluxes that will allow the irradiations to achieve the burnup and fast fluence requirements in a shorter period of time, approximately 18 months versus 30 months in a large $\mathrm{B}$ position. The increased fast to thermal neutron flux ratio in the NEFT also required tailoring of the neutron flux spectrum to prevent exceeding the maximum fast fluence limit before the fuel burnup goals were achieved. However, the acceleration factor between these ATR experiments and the VHTR for fuel burnup and fast neutron fluence accumulation will remain at or below three to prevent premature fuel particle failures. Since the NEFT position is almost four times the diameter of the large B positions, AGR-3/4 and the other later experiments will be much larger in size and different in shape compared to AGR-1 and AGR-2. This much larger irradiation position also supports irradiating two experiments simultaneously (as previously planned) by doubling them up into irradiations with essentially twice as many capsules. The doubling process will most effectively use the larger position to reduce the irradiation time required and therefore obtain the necessary fuel burnup and fast fluence levels as early as practical. The schedule advantage of using the NEFT position is demonstrated in the irradiation schedules for AGR-2 versus AGR-3/4. The irradiation of AGR-2 was started in June 2010, and the irradiation of AGR-3/4 was started approximately 18 months later in December 2011. However, the irradiation of these two experiments is currently scheduled for completion in April 2013 for AGR-2 and only approximately seven months later for AGR-3/4 in November 2013.

\section{FUEL AND IRRADIATION DETAILS}

The following subsections describe the two types of fuel particles used in the AGR-3/4 experiment as well as the irradiation requirements.

\section{III.A. Fuel Details}

The AGR-3/4 fuel is comprised of two different types of fuel particles [2]. The majority of the fuel particles being used to create the fuel compacts will provide the irradiation temperatures and conditions for the experiment. These particles are typically called 'driver' particles, since they serve similar functions to the driver fuel elements used in the core of a test reactor. The driver particles were made from uranium oxycarbide (UCO) type LEU fuel kernels originally fabricated for AGR-1 with an enrichment level of $19.7 \%$. The fuel particles are comprised of LEU fuel kernels, which are covered with a layer of silicon carbide, sandwiched between two pyrolytic carbon layers to make up the TRISO-coated fuel particles. The fuel particles are over-coated with a 
mixture of graphite powder and thermo-set resin, and then pressed into fuel compacts that are then sintered to remove the volatile compounds in the resin. After being covered with the TRISO coatings, the $350 \mu \mathrm{m}$ nominal diameter fuel kernels result in approximate $820 \mu \mathrm{m}$ nominal diameter fuel particles.

The second type of fuel particles in the AGR-3/4 fuel compacts are the DTF particles mentioned earlier. The DTF particles were made using UCO type LEU fuel kernels from the same batch used for the driver particles. However, the DTF particles only contain a thin carbon buffer layer and single pyrolytic carbon layer resulting in an approximate overall particle diameter of $425 \mu \mathrm{m}$. Since the DTF particles do not contain a silicon carbide layer or the second pyrolytic carbon layer, these particles are anticipated to fail the single pyrolytic carbon layer and release fission products to the fuel compact and graphitic materials in the experiment capsule early in the irradiation. The puff of released fission gases will be detected by the gross gamma detectors in the fission product monitors indicating when the particle failures occurred, and subsequent PIE analysis of the capsule contents will provide the fission product retention data desired from the experiment.

The height of the AGR-3/4 fuel compacts was reduced to increase the number of fuel compacts available for the planned PIE tests and measurements and to minimize the neutron fluence gradients within each compact. The nominal height of $25 \mathrm{~mm}$ used in the previous AGR-1 and AGR-2 experiments was decreased to $12.5 \mathrm{~mm}$. However, the diameter of the AGR-3/4 fuel compacts was maintained at the same nominal $12.4 \mathrm{~mm}$ value used in the earlier experiments. Since the compact height was reduced, the number of fuel particles in each compact was also reduced from the approximate 4,150 fuel particles in AGR-1 to approximately 1,910 fuel particles total, including 20 DTF particles. The mean total uranium content of in an AGR-3/4 fuel compact from both driver and DTF particles is approximately 0.45 grams.

\section{III.B. Irradiation Details}

The twelve capsules in AGR-3/4 experiment will provide data in different combinations of irradiation temperature, fuel burnup, and material types/configurations. Five of the capsules were selected to be controlled based on time average peak fuel temperatures with one capsule at $<900^{\circ} \mathrm{C}$, two capsules at $<1100^{\circ} \mathrm{C}$, one capsule at $<1250^{\circ} \mathrm{C}$ and one capsule at $<1300^{\circ} \mathrm{C}$. The other seven capsules are being controlled based on time average peak graphite and fuel matrix material temperatures ranging from $950^{\circ} \mathrm{C}$ to $1180^{\circ} \mathrm{C}$. Controlling fuel temperatures alone could result in significant temperature variations over the life of the irradiation in the surrounding materials. Therefore, utilizing a temperature control strategy in both fuel and surrounding materials will provide data under both conditions to help separate the effects of fuel versus material temperatures on fission product migration.

AGR-3/4 will be utilizing the full 1.2 meter active core height in ATR to provide the desired broad range of fuel burn-up and temperature combinations. The burnup goals are a minimum of $6 \%$ FIMA and a maximum of less than $19 \%$ FIMA. The anticipated burnup ranges from less than $12 \%$ FIMA for the very top and bottom capsules exposed to the lowest neutron flux to close to the maximum burnup for the capsules at the peak neutron flux located at the vertical center of the ATR core.

\section{CAPSULE AND CONTROL AND MONITORING SYSTEM DESIGNS}

The following subsections provide details of the irradiation capsule and test train design as well as the monitoring and control systems design and function.

\section{IV.A. Capsule Design}

A horizontal cross-section of the AGR-3/4 experiment capsule is shown in Figure 2 below.

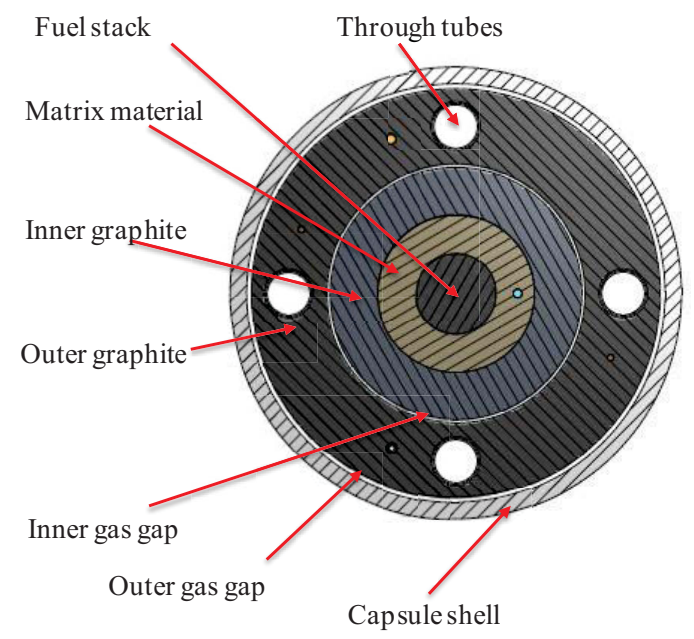

Fig. 2: AGR-3/4 capsule cross-section 
The overall concept for the AGR experiment capsules is very similar for all of the irradiations. However, the design of the experiment capsules, which was essentially identical for the first two irradiations (AGR-1 and AGR-2), has been significantly modified for AGR-3/4. The change was needed primarily to support the different mission and purpose of AGR-3/4 as well as to accommodate the new type of irradiation position that will be utilized. As indicated earlier, the AGR-3/4 irradiation, as well as the other subsequent AGR irradiations, will be performed in the much larger NEFT irradiation position in the ATR to reduce the overall irradiation schedule of the AGR experiments.

Each AGR-3/4 capsule contains four right circular cylindrical fuel compacts nominally 12.4 $\mathrm{mm}$ in diameter and $12.5 \mathrm{~mm}$ long. The fuel compacts are arranged in a single stack in the center of the capsule, surrounded by a solid ring of fuel matrix material. The next ring is made of one of two nuclear grade graphites being considered for use in the NGNP core. An inner insulating gas gap separates the inner graphite from an outer ring of the same nuclear grade graphite, which is operated at a relatively cool temperature of $600^{\circ} \mathrm{C}$ to collect any fission products that migrate completely through the matrix material and inner graphite rings. The outside diameter of the outer graphite forms the inside boundary of the outer insulating gas gap that provides the primary temperature control during irradiation. Both the inner and outer graphite components have spacer nubs machined on their outside diameters to space them away from the component next to them to form the applicable gas gap for temperature control. The thickness of the outer gas gap varies among the capsules from approximately $0.25 \mathrm{~mm}$ to $1.0 \mathrm{~mm}$ thick depending on the neutron flux at the vertical location of the capsules within the ATR core. The thickness variation in the outer gas gap was accomplished by varying the outside diameter of the outer graphite.

As in the other AGR experiments, no metal could touch the fuel particles so the thermocouples had to be placed within one of the graphite or matrix material rings within the experiment capsules. The outer graphite ring was selected for placement of the thermocouples for four very good reasons. First, the temperatures in the outer graphite are relatively low, which would significantly increase the longevity of the thermocouples and allow use of smaller $(1 \mathrm{~mm})$ diameter (type N) thermocouples. Second, because of their smaller size, there was enough room within the through tubes to accommodate nominally two thermocouples in addition to the inlet and outlet gas lines for each capsule. Third, the smaller thermocouples are much more flexible, which was very beneficial in making the relatively tight bends in the thermocouples within the very limited space of the gas plenums between capsules. The final and fourth reason was the smaller thermocouples provided enough room for three capsules (nominally designed for fuel centerline temperatures of $900^{\circ} \mathrm{C}$, $1000^{\circ} \mathrm{C}$ and $1100^{\circ} \mathrm{C}$ ) to have a third thermocouple located in the matrix material next to the fuel compacts. These additional thermocouples were placed in the matrix material next to the fuel compacts to provide measured temperature data inside of the inner gas gap. The temperature data from these three thermocouples could be used to more accurately reconcile the thermal analysis model and improve the accuracy of the model predictions for the fuel, matrix material and inner graphite temperatures in all capsules.

The through tubes (pathways for thermocouples and gas lines from the lower capsules to pass through the upper capsules) were positioned in the middle of the outer graphite to minimize their effect on the sorption of the fission products. Melt wires were included in each capsule for passive temperature verification in the relatively unlikely event (due to the lower temperatures) that all thermocouples within a capsule were to fail during irradiation. Flux wires were also installed in the graphite to measure both the thermal and fast neutron fluence.

\section{IV.B. Test Train Design}

The AGR-3/4 experiment test train is very similar to AGR-1 and AGR-2. Twelve separate stacked capsules were welded together to form the core section of the test train. The core section is welded to an umbilical tube (termed a leadout at ATR) that houses and protects the gas lines and thermocouple leads. The leadout is routed from the NEFT position straight up from the ATR core to the experiment penetration in the reactor vessel top head. Above the vessel top head, the gas lines and thermocouple leads are connected to their facility counterparts in the temperature monitoring, control and data collection system similar to the other AGR experiments. The lead-out also vertically locates the experiment within the NEFT (shown in Figure 1) in the ATR core. A vertical section of the AGR-3/4 test train is shown in Figure 3. 


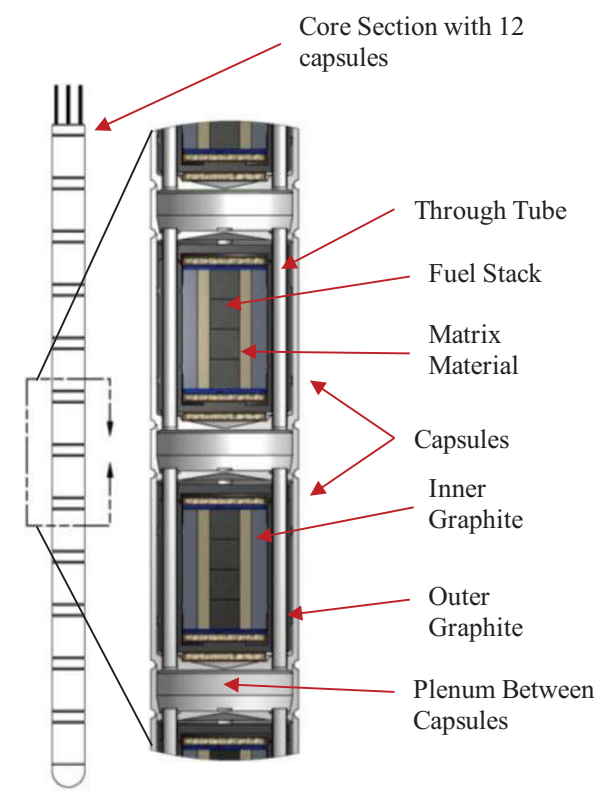

Fig. 3: AGR-3/4 test train vertical section

The original AGR-3 and AGR-4 experiments were both necessary to obtain data at the different combinations of irradiation conditions necessary to support development of the fission product transport models. Therefore, the desired number of capsules for this irradiation was twice the nominal six capsules originally envisioned for each irradiation. Doubling the number of capsules required use of the full 1.2 meter ATR active core height (versus 0.9 meters used in AGR-1 and AGR-2). In addition, the overall capsule height (with gas plenums between capsules) was reduced from $150 \mathrm{~mm}$ in AGR-1 and AGR-2 to approximately $110 \mathrm{~mm}$. Capsules towards the top and bottom of the core (as well as the fuel compacts within these capsules) in this arrangement have increased vertical neutron flux gradients, which was also a major factor in the decision to reduce the height of the fuel compacts for AGR-3/4.

To maximize the irradiation space available as well as tailor the neutron flux spectrum to more closely approximate the neutron spectrum in the NGNP, a new flux trap irradiation housing was designed for this specific experiment (see Figure 4). The irradiation housing interfaces with the ATR core structure that supports the ATR fuel elements surrounding the NEFT, and the housing also locates the AGR-3/4 test train in the center of the NEFT. The neutron spectrum was tailored to reduce the fast to thermal neutron flux ratio to prevent excessive fast neutron damage while achieving the desired fuel burnup. The housing also helps lower the overall thermal neutron flux rate to keep the irradiation acceleration factor to less than three and prevent possible premature fuel particle failures. Furthermore the NEFT is the primary irradiation position within the northeast quadrant of the ATR, and its power level is controlled by the four control drums (see Figure 1) on its north and east sides. The irradiation program utilizing the NEFT has the ability to determine the power level (within specified limits) in the northeast quadrant, which was the key parameter in limiting the irradiation acceleration factor. Controlling the power level is also crucial in flattening the heat generation rate within the AGR$3 / 4$ fuel compacts to achieve the constant desired irradiation temperatures in the experiment.

The irradiation housing consists of inner and outer stainless steel shells with a hafnium filter sandwiched between them. The outer shell has centering collars with spacer nubs on them located at the top and bottom of the housing (above and below the active core height of ATR) to provide a uniform reactor coolant water channel between it and the ATR core structure. In the same manner, there are spacer nubs on the AGR-3/4 test train to ensure a uniform reactor coolant water channel between the test train and the irradiation housing. The center section of the irradiation housing located within the active core height of ATR contains a very wide water coolant channel located vertically between the centering collars that are shown in pink in Figure 4. In addition to its cooling function, the reason this channel is exceptionally wide is to moderate the neutrons coming from the ATR driver fuel and therefore reduce the fast to thermal neutron flux ratio. The hafnium filter in the housing next to the test train then helps reduce the thermal neutron flux along with the power level adjustments to maintain the low irradiation acceleration factor. It should be noted that a consumable neutron poison (e.g. boron carbide) could not be used in the graphite in this irradiation since it might affect the fission product retention behavior of the graphite. The design of the irradiation housing required a very close coordinated effort between its design, the test train design, and the reactor physics and thermal analyses. Meeting the neutron flux requirements was one of the biggest challenges in the design of the AGR-3/4 experiment. Of course there were many other design challenges in providing the relatively large number of capsules with widely different irradiation temperatures combined within a single test train. 
Proceedings of the HTR 2012

Tokyo, Japan, October 28 - November 1, 2012

Paper HTR2012-3-028

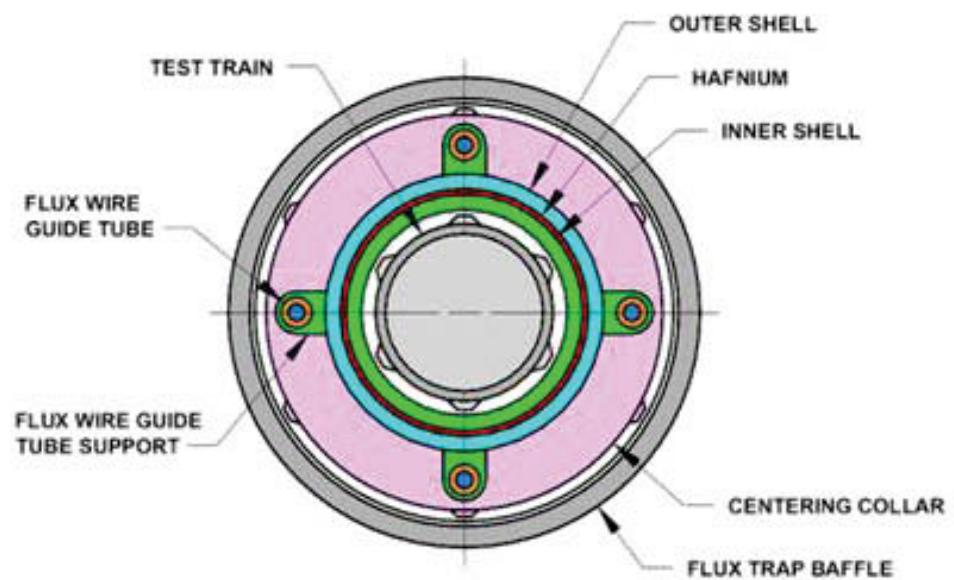

Fig. 4: AGR-3/4 irradiation housing cross-section

\section{IV.C. Temperature Control System}

Since most of the AGR-3/4 irradiation will be concurrent with the AGR-2 irradiation, a second temperature control system was needed.

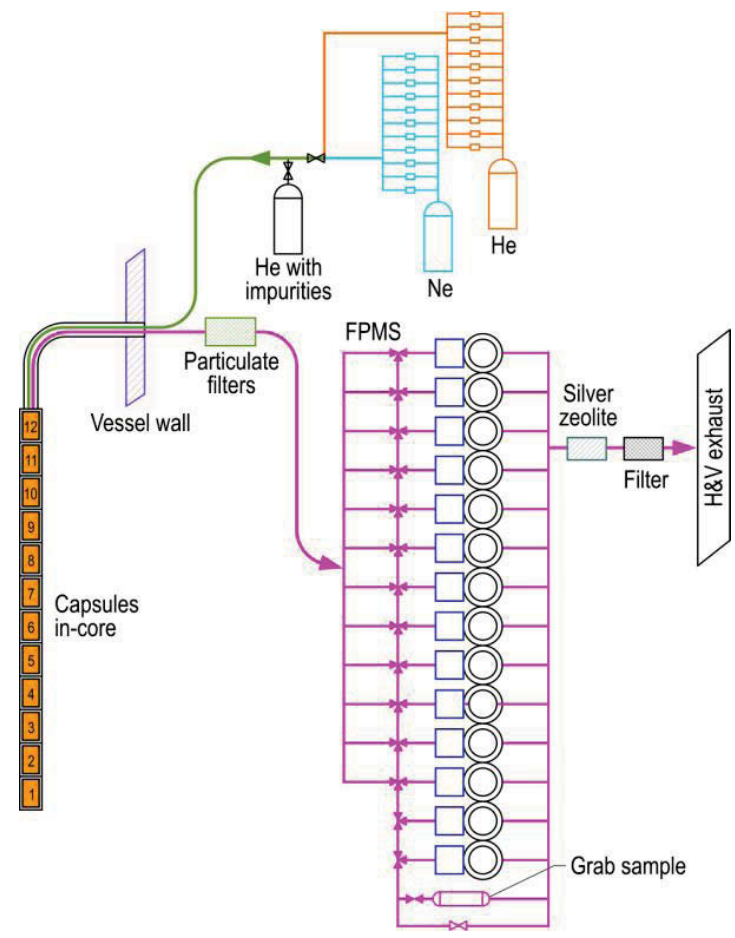

Fig. 5: AGR experiment gas flow path
The new system has fourteen temperature control channels (one for each capsule, one for the leadout, and an installed spare). The new system is essentially a doubled-up version of the original AGR-1 system, and is shown in Figure 5.

Each capsule has its own custom blended gas supply and exhaust for independent temperature control and fission product monitoring. The desired temperatures in the experiment capsules are achieved by adjusting the mixture ratio of two different gases with opposing thermal conductivities to control the heat transfer across the two insulating gas gaps between the heat source (fuel fissions and gamma heating of capsule materials) and the capsule wall that is in direct contact with the relatively cold ATR primary coolant $\left(52^{\circ} \mathrm{C}\right)$. Helium is used as the high (thermally) conductive gas and neon is used as the insulating gas. Neon (versus argon that can provide a wider temperature control band) is typically used in fuel irradiations such as the AGR experiments for the insulating gas to prevent activated argon gas from overwhelming the fission product monitors. Computer controlled mass flow controllers are used to automatically blend the gases (based upon feedback from the experiment thermocouples) to control the thermocouple temperatures, which are analytically coupled to the fuel specimen temperatures. Two thermocouples are located in the outer graphite (shown in Figure 2) inside each experiment capsule, and one thermocouple is designated for primary control of the capsule temperature. In the event the control thermocouple fails open (as indicated by a significant increase in resistivity); temperature control for the capsules will 
automatically be switched over to the designated back-up thermocouple, which will then be designated as the new control thermocouple. As indicated earlier, a third thermocouple was included in three select capsules to help reconcile the thermal analysis model by providing temperature data across the inner gas gap in the capsules. A more detailed description of the AGR temperature control system design and functions can be found in Reference [3].

The AGR-3/4 irradiation had a new additional requirement to inject the anticipated types and levels of gas impurities anticipated in the NGNP into the temperature control sweep gas of a maximum of six experiment capsules. The purpose of this requirement is to determine the possible effects of the gas impurities on the fuel and other capsule materials. Capsules at different temperatures were initially selected for the sweep gas containing impurities so the results could be compared to other capsules at the same temperatures without the gas impurities. The system was designed to utilize a helium carrier gas supply containing carbon monoxide, hydrogen and moisture impurities that could be injected into the temperature control gas of the selected capsules downstream of the neon and helium mixing tee. The flow rate of the impurity injection system is a very low percentage of the temperature control gas (e.g. $0.5 \mathrm{sccm}$ of $30 \mathrm{sccm}$ ) to minimize the effect of the additional helium and impurities on the temperature control of the capsules. The carrier gas and impurity concentrations are

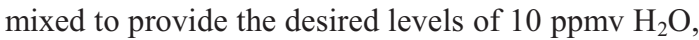
50 ppmv $\mathrm{CO}$, and $50 \mathrm{ppmv}_{2}$ in the total $30 \mathrm{sccm}$ temperature control gas supply to the affected capsules. The capability to obtain weekly grab samples upstream of the experiment capsules was provided to verify the correct impurity levels are being supplied to the capsules. In addition, the capability to take grab samples downstream of the capsules, which has been provided on all AGR experiment capsules, can be used to measure the change in impurities in the exhaust gas from the capsules. The impurity injection system is anticipated to be utilized on the later AGR irradiations including AGR-5/6.

\section{IV.D. Fission Product Monitoring System}

In order to minimize temperature changes and maintain the temperature as constant as possible, the temperature control gas system provides a continuous flow to each specimen capsule. Monitoring this continuous gas flow for fission gases provides valuable information on the fuel performance during irradiation. As shown in figure 5 , the outlet gas from each capsule is routed to its individual fission product monitor, and the gas flows can be rerouted to an online spare monitor if any of the primary monitors experience detector or other failures.

The fission product monitors consist of a high purity germanium spectrometer for identifying and quantifying the fission gas nuclides and a sodium iodide liquid scintillation gross gamma detector to provide indication when a puff release of fission gases passes through the monitor. The gross gamma detector also provides the release timing. With the combination of a gross gamma detector and a spectrometer being continuously on-line, the gross gamma detector results can be scanned quickly to determine which portions of the voluminous spectrometer data need to be closely scrutinized. A puff release of fission gases typically indicates when a TRISO fuel coating failure may have occurred. Through identification and quantification (with uncertainties) of the isotopes, the spectrometer can be used to determine the isotopic release-to-birth ratio (with uncertainties) of the fission gases being detected. The determination of the release-to-birth ratios can establish whether a new TRISO fuel coating failure has occurred or if the fission products are merely being released from an existing failure or uranium contamination on the outside surface of the fuel particles. These details can be very important in the testing of small TRISO particle fuels, where the particle failures need to be tallied very accurately to support statistical qualification of the fuel or development of improved fuel performance and fission product transport models to support source term analysis for a VHTR. The fission product monitoring system was designed and response modeled to detect and quantify each individual fuel particle failure up to and including a very unlikely 250th fuel particle failure. A more comprehensive description of the AGR fission product monitoring system design and functions can be found in Reference [3].

As indicated earlier, the AGR-3/4 and later irradiations will be doubled up, with the test trains containing up to twelve experiment capsules controlled by the twelve new temperature control channels discussed earlier. Therefore the new fission product monitoring system installed for AGR-3/4 contains twelve primary monitors plus two spare monitors. The new monitors are duplicates of the original monitors that have performed exceptionally 
well on the AGR-1 and AGR-2 experiments. The new system has two on-line spare monitors so the ratio of spare monitors to prime monitors is the same as the existing system (e.g. one spare for each six prime monitors). The new system also has the capability of re-routing the effluent of any capsule to either spare monitor to maximize the flexibility of the system.

\section{EXPERIMENT HISTORY AND STATUS}

The following subsections provide details on the schedule and status, irradiation experience and results of AGR-3/4 experiment irradiation.

\section{V.A. Schedule and Status}

The feasibility study for the AGR-3/4 irradiation was performed in 2008, and the preliminary design review was conducted on August 2010. The final design of the test train and new temperature control, impurity injection and fission product monitoring systems was performed in early February 2011. Fabrication, assembly and testing of the test train and the control and monitoring systems installations were completed in November 2011. Insertion of the experiment into the ATR core was performed in early December and irradiation was initiated in mid December 2011. To achieve the desired fuel burnup and fast fluence requirements, the experiment will require approximately 400 Effective Full Power Days (EFPDs) of irradiation in the ATR. The AGR$3 / 4$ irradiation is currently anticipated to be completed in late calendar 2013.

\section{V.B. Irradiation Experience}

In order to prevent excessive stresses resulting from the very high temperature gradients experienced in the AGR irradiation capsule materials, the capsule design includes a very tight tolerance slip fit between the through tubes and the capsule bottom heads. This slip fit introduces a possible leakage path between capsules. However, leakage between capsules (e.g. cross-talk) is prevented by an inert gas overpressure in the leadout portion of the test train that ultimately flows into the plenums between capsules. The gas overpressure or flow rate into the leadout then results in gas leaking from the plenums into all of the capsules [3]. The in leakage of the gas from the plenums prevents gas out leakage from the capsules to the plenums that could result in capsule cross-talk. The gas supplied to the leadout can be either helium or neon, depending on the stage of the irradiation, since it will slightly down blend the temperature control gas mixture. In order to minimize the down blending effect of the leadout gas in leakage, the minimum flow rate required to prevent cross-talk between capsules must be determined. This minimum flow rate is accomplished by using the fission product monitors to detect leakage (or absence of leakage) of activated neon between capsules at different plenum flow rates in the very beginning of the experiment irradiation. The leadout minimum flow rate testing along with measuring the gas delivery time between the capsules and their fission product monitors for AGR$3 / 4$ was completed in the first week or so of irradiation.

The experiment was then taken to temperature, which identified the need to increase the power in the NEFT by approximately $10 \%$ to achieve temperature in several of the capsules. After the power increase was completed in the second week of irradiation, there were only three capsules ranging from approximately $50^{\circ} \mathrm{C}$ to $140^{\circ} \mathrm{C}$ below their target temperatures, and nine of the capsules were within their target temperature ranges.

Very early in the third week of irradiation, the DTF particles started to fail, and by January $2^{\text {nd }}$, DTF particle failures had been detected in all but four capsules. In order to prevent unwanted variables in the data, the need to maintain constant temperatures in the capsules then became more important than necessarily achieving the initial temperature targets, so the decision was made to readjust the temperature ranges of the three low temperature capsules to their current temperatures. In a similar vein, the impurity injection system will not be activated until all DTF particles have failed in the selected capsules and the fission product release has stabilized.

The DTF particle failures also resulted in very high count rates in the fission product monitors; however, collimators were changed in the monitors and the system continues to perform very well. There were also personnel access restrictions to the fission product monitoring system as a result of some almost undetectably small gas line leaks that were repaired at the end of the first cycle of irradiation in mid February. Overall, the performance and results of the irradiation have been very good. 


\section{V.B. Results to Date}

The irradiation had completed 78 EFPDs of irradiation out of the approximate 400 EFPDs scheduled for this experiment by the end of March 2012. The fuel had attained an approximate peak burnup of $4.2 \%$ FIMA during that time. DTF fuel particle failures have been detected in all capsules to different degrees depending on location of the capsule with respect to the axial neutron flux profile of the ATR. At the end of March 2012, the highest burn-up capsules at the vertical center of the ATR core appear to have essentially experienced failure of all DTF particles. At the same time, there have been approximately $25 \%$ of the DTF particles fail in the very top and bottom capsules at the edges of the ATR core, with the DTF particle failures in the intermediate capsules varying from slightly over $60 \%$ to over $90 \%$ of the total DTF particles. The preliminary results indicate the fuel is performing exactly as designed and the irradiation is progressing very well.

\section{CONCLUSIONS}

The insights and lessons learned from AGR-1 have been incorporated into the design, assembly and early irradiation of AGR-2, and then rolled into the design of AGR-3/4. AGR-3/4 has presented new design challenges, which have been resolved with multiple new design features. An additional system to inject the anticipated NGNP coolant gas impurities into the AGR-3/4 irradiation sweep gas was included in the experiment requirements.

This irradiation will provide valuable data for the qualification of gas reactor particle fuel by updating and improving the fission product transport and fuel performance models for the NGNP.

\section{ACKNOWLEDGMENTS}

This work was supported by the United States Department of Energy (DOE) under DOE Idaho Field Office Contract Number DE-AC0705 ID 14517.

\section{REFERENCES}

[1] Petti, D. A., et al, "Technical Program Plan for the Advanced Gas Reactor Fuel Development and Qualification Program", Idaho National Laboratory Report INL/EXT-05-00465, Revision 1 (August 2005)
[2] Hunn, J. D., et al, "Fabrication and Characterization of Driver Fuel Particles, Designed-to-Fail Fuel Particles, and Fuel Compacts for the US AGR-3/4 Irradiation Test", Proceedings of the HTR2012, Tokyo, Japan, October 28 - November 1, 2012, Paper HTR2012-3-026

[3] Grover, S. B., and Petti, D. A., "Initial Irradiation of the First Advanced Gas Reactor Fuel Development and Qualification Experiment in the Advanced Test Reactor", Proceedings of Global 2007 Advanced Nuclear Fuel Cycles and Systems, Boise, ID, USA, September 9-13, 2007, Paper 177457 